\title{
Representaciones discursivas: valoraciones a la comunidad gay en comentarios de ciberprensa chilena
}

\author{
Discourse representations: appraisals of the gay community in the Chilean cyber \\ press
}

\author{
Claudio Araya Seguel ${ }^{2}$
}

\begin{abstract}
Resumen
En los últimos años se han producido cambios jurídicos que buscan un nuevo trato hacia la comunidad de lesbianas, gays, bisexuales, transexuales, intersexuales (LGBTI) en Chile. Estos cambios se han materializado en legislaciones como la Ley Antidiscriminación y la Ley de Acuerdo de Unión Civil (AUC) que entró en vigencia en el mes de octubre de 2015, además de decisiones políticas como la difusión de un cuento sobre una familia homoparental en la red estatal de jardines infantiles. La duda que surge ante este panorama es si el discurso mediático y de los lectores chilenos de ciberprensa está en sintonía con esos cambios impulsados desde el Estado. En este contexto, este artículo examina críticamente las representaciones discursivas acerca de la comunidad LGBTI que se configuran en foros de opinión en dos periódicos de perfil conservador. Dichas representaciones discursivas se obtienen a partir de un análisis linguístico de los complejos clausulares presentes en los comentarios desde el sistema semántico VALORACIÓN. El objetivo es examinar de qué manera, a través del discurso de los lectores, se configura la identidad social de la comunidad gay y cómo a través de recursos lingüísticos se ejerce un tipo de discriminación homofóbica. Los resultados más destacados indican que en general se evalúa negativamente tanto a la comunidad gay como al cuento homoparental. Dicha evaluación se ampara en JUICIO de sanción y de estima social vinculado a anormalidad e inmoralidad y un COMPROMISO heteroglósico que reconoce las posiciones de la diversidad a través de la contracción dialógica.
\end{abstract}

Palabras clave: Comunidad gay, VALORACIÓN, representaciones discursivas, ciberprensa

\begin{abstract}
In recent years there have been legal changes that seek for a new treatment for the lesbian, gay, bisexual, transsexual, intersex (LGBTI) community in Chile. These changes have materialized in legislation such as the antidiscrimination and the Civil Union Agreement (AUC) laws enforced in October 2015, as well as political decisions such as the publication and distribution of a story about a homoparental family in the network of State kindergartens. The doubt that arises in this scenario is whether the media discourse and the Chilean readership of cyberpress is in tune with these changes coming from the State. In this context,

\footnotetext{
${ }^{1}$ Este trabajo se inscribe dentro de la investigación de tesis doctoral 'Concepciones ideológicas acerca de la comunidad gay y sus representaciones discursivas en textos de ciberprensa chilena (2012-2017)'. Doctorado en Lingǘstica de la Facultad de Letras, Universidad Católica de Chile. La investigación cuenta con el apoyo de beca Conicyt para estudios de posgrado.

${ }^{2}$ Candidato a Doctor en Lingüística. Universidades Católica y de Santiago de Chile. E-mail: claurayas@gmail.com
} 
this article critically examines the discursive representations about the gay community in opinion forums in two newspapers with a conservative profile. These discursive representations are obtained from a linguistic analysis, from the semantic value system, of the clause complexes found in the comments. The objective is to examine how, through readers' discourse, the social identity of the gay community is configured and how a type of homophobic discrimination is exercised through linguistic resources. The most salient results indicate that the gay community and the homoparental story are generally negatively evaluated. This evaluation is based on a sanction judgment and social esteem linked to abnormality and immorality and a heteroglossic commitment that recognizes the positions of diversity through the dialogic contraction.

Keywords: Gay community, Appraisal, discursive representations, cyberpress.

\section{Introducción}

Este artículo examina las representaciones discursivas acerca de la comunidad gay difundidas por dos ciberperiódicos de perfil conservador (Guerrero \& Müller, 2012), como latercera.com y emol. com desde la noticia de la publicación y distribución del cuento "Nicolás tiene dos papás" en los jardines infantiles de la Junta Nacional de Jardines infantiles (Junji). El trabajo busca examinar desde el modelo de VALORACIÓN (Hood, 2010; Kaplan, 2004; Martin, 2003; Martin \& Oteíza \& Pinuer, 2012; White, 2005; White, 2010) desarrollado en el marco de la Lingüística Sistémico Funcional (en adelante LSF) cómo los lectores que intervienen en los foros representan discursivamente a los gay a partir del contexto de la difusión de la noticia. En este sentido, la pregunta que persigue responder este estudio es ¿cuáles son las representaciones discursivas acerca de la comunidad gay que se evidencian en los comentarios de ciberprensa?

La noticia de la publicación del cuento homoparental reviste gran importancia para las organizaciones de diversidad sexual: se trata del primer documento emanado desde el Estado que recoge el tema de las familias homoparentales y se publica en el contexto de una creciente discusión en la sociedad chilena acerca de la necesidad de regular los vínculos afectivos entre personas del mismo sexo. Los intentos por regular las relaciones entre personas del mismo sexo se pueden observar en algunas notas periodísticas que informan acerca de la presentación al gobierno de un proyecto de ley de matrimonio igualitario impulsado por la fundación Iguales y la Universidad de Chile. Conviene tener presente que la discusión respecto al matrimonio igualitario se origina en el año 2012. Ese año tres parejas del mismo sexo demandan al Estado de Chile ante la Comisión Interamericana de D.D.H.H (CIDH) por denegar el derecho al Matrimonio Igualitario. Se llega a una solución amistosa en la que el Estado de Chile se compromete a presentar un proyecto de ley de Matrimonio Igualitario. Esto obligó al gobierno de Michelle Bachelet (2014-2018) a incorporarlo en su programa de gobierno y a asumir el compromiso del envío del proyecto en atención a los plazos fijados en el acuerdo de solución amistosa llevado a cabo por el MOVILH, el Estado de Chile y la CIDH.

Se trata de un estudio cualitativo, descriptivo e interpretativo que busca acceder a los significados interpersonales que subyacen a las representaciones discursivas de la comunidad gay (actores sociales), publicación y difusión del cuento (evento) y el cuento homoparental (objeto) desde las categorías analíticas contempladas en el sistema de VALORACIÓN (Hood, 2010; Martin, 2003; Martin \& White, 2005; Oteíza \& Pinuer, 2012).

De este modo, se busca explorar los significados interpersonales y evidenciar los recursos lingüísticos valorativos que se emplean para representar a los actores sociales, el evento y el objeto en los comentarios de ciberprensa referidos al cuento homoparental. Desde esa descripción

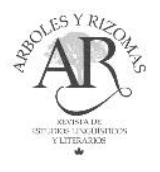


de las categorías analíticas del modelo de VALORACIÓN, posteriormente, esbozaremos algunas interpretaciones en cuanto a los recursos valorativos y el contexto sociopolítico de la situación de la comunidad gay, considerando que, desde la perspectiva de la LSF, la elección de los recursos lingüísticos está moldeada por la configuración contextual (Halliday \& Matthiessen, 2014; Martin \& Rose, 2007).

Se seleccionaron aleatoriamente 10 comentarios (5 de latercera.com y 5 de emol.com) y en ellos se observó el comportamiento del sistemas de VALORACIÓN empleado para aludir a la comunidad gay (actores sociales), evento (publicación y difusión del cuento) y objeto (el cuento). De esos 10 comentarios, se presentan algunos ejemplos en los que se evalúa distintas entidades discursivas.

\section{Contextualización}

\subsection{Antecedentes acerca de la situación de la comunidad gay ${ }^{3}$}

En los últimos años, la sociedad chilena se ha abierto a la discusión de temas que históricamente han producido controversia, como lo demuestra la promulgación del Acuerdo de Unión Civil (AUC) (entró en vigencia en octubre de 2015), la Ley Antidiscriminación (denominada Ley Zamudio) y la presentación al gobierno de proyectos de Matrimonio Igualitario, el último de ellos durante los últimos meses del gobierno de Michelle Bachelet (2014-2018).

Uno de esos temas controversiales es la diversidad sexual, específicamente, la regulación legal de las parejas del mismo sexo y sus familias construidas. Chile ha visto cómo dentro de nuestro continente se han aprobado legislaciones (Ley de Matrimonio Igualitario) que ofrecen un nuevo trato a la comunidad gay, con lo que se ha validado la familia homoparental como una de las tantas formas de hacer y constituir una familia.

Colombia (2016), Brasil (2013), Uruguay (2013) y Argentina (2010) han legalizado el matrimonio igualitario en Sudamérica y han marcado un camino de respeto por la diversidad sexual amparado a su vez en la necesidad de trato igualitario de las personas ante la ley. En efecto, las Constituciones de estos países (incluyendo la chilena) plantean que todo ciudadano es igual ante la ley, por lo que se trata de un problema de respeto por los derechos humanos, de acuerdo a lo planteado por diversas agrupaciones defensoras de la diversidad sexual como MUMS (Movimiento unificado de minorías sexuales), MOVILH (Movimiento de integración y liberación homosexual), y la Fundación IGUALES. Este trato igualitario hacia las personas disruptivas de la norma sexual, evidentemente no se materializa ni en el plano interpersonal privado ni en el ámbito legal e institucional, pues las parejas del mismo sexo experimentan dramáticamente una serie de injusticias al -por ejemplo- no existir regulación de los bienes adquiridos o al carecer de una figura legal que ampare las relaciones afectivas de hecho. El AUC ha subsanado estas cuestiones, sin embargo, esta legislación no contempla el tema de la filiación.

\footnotetext{
${ }^{3}$ Según Núñez Noriega (2015), podemos hablar de 'comunidad gay' pues en ella se reconoce un 'habitus grupal homosexual', es decir, una serie de disposiciones que orientan las formas de actuar y de pensar de las personas a partir de la conciencia de su diferencia respecto a la mayoría. La forma de expresar semióticamente ese 'habitus', desde la perspectiva de Newton (1972) y Sontag (1984) es el camp, esto es, una estética que exagera la valoración de lo femenino y está asociado al espectáculo del transformismo. Esa estética camp, según Contardo (2011), incluye una serie de claves o códigos lingüísticos vinculados a la ironía, el doble sentido y la relevancia del subtexto. Además, el camp lleva consigo un humor típicamente gay, denominado camping por Newton (1972).
} 
Muchas personas homosexuales son despojadas de sus pertenencias al morir sus parejas por parte de sus familias las que rechazan esos vínculos por razones religiosas o la potencia de la heteronorma ${ }^{4}$, por lo que se aprecia, de acuerdo con Farías (2015), una homofobia latente, a pesar de que en Chile, a partir del crimen de Daniel Zamudio (Fluxá, 2014) exista la Ley Antidiscriminación que hemos mencionado.

Ante este panorama, en Chile estamos atrasados en cuanto a dichas legislaciones. Solo en enero de 2015 el parlamento chileno logra despachar el Acuerdo de Unión Civil (AUC) que regula las relaciones de hecho tanto homosexuales como heterosexuales. Sin embargo, en Chile aún no existe un cuerpo legal que ofrezca la posibilidad de contraer matrimonio a las personas del mismo sexo con lo que se sigue perpetuando un trato desigual por orientación sexual e identidad de género.

Esta discusión en torno a la regulación de la vida en pareja, especialmente de las parejas homosexuales, trae consigo una arista más compleja: la adopción de niñ@s. Con todo, la inminente regulación trae consigo una emergente concepción de la familia que es una realidad, pero que no está respaldada en la legislación: la familia homoparental.

\subsection{Publicación y difusión del cuento homoparental "Nicolás tiene dos papás"}

La discusión acerca de la regulación de las parejas del mismo sexo no recoge el tema de la filiación en el AUC. Por esto, el proyecto de Matrimonio Igualitario busca incorporar la adopción de niñ@s por parte de parejas gay. Frente a la eventual validación legal de la familia homoparental, instituciones como la Iglesia Católica y algunos sectores conservadores de partidos políticos (UDI, RN y sectores de la DC) han planteado su rechazo tanto a la regulación de las uniones como a la familia homoparental.

En este contexto, el Movilh en conjunto con otros organismos (Junta Nacional de Jardines Infantiles (JUNJI), el Departamento de Psicología de la Universidad de Chile y otras instituciones chilenas), financiado por la Embajada de la Unión Europea y de la Embajada del Reino de los Países Bajos, promovió la publicación y difusión de un cuento para niños que busca desde temprana edad generar conciencia del respeto y validez de las diversas formas de personas y familias: "Nicolás tiene dos papás" (Movilh, 2014). La publicación del relato generó controversia en distintos ámbitos públicos, pues se trata de un documento emanado del Estado de Chile para ser difundido en todas las instituciones educativas como jardines infantiles de JUNJ, si las comunidades educativas así lo determinan.

La emergencia de este hito ${ }^{5}$ en la sociedad chilena generó polémica al despertar un acalorado debate respecto a la situación de los niñ@s integrantes de familias homoparentales. En este sentido, grupos conservadores religiosos y sectores de partidos políticos de derecha como la UDI y RN levantaron la voz contra lo que consideraron un "descriterio" por parte del Estado, pues -según ellos- las familias homoparentales no son normales. Además acusaron al gobierno de

\footnotetext{
${ }^{4}$ Desde la perspectiva de Pollak (1987), la manera de concebir culturalmente la categoría 'homosexual' está fuertemente determinada por la heteronormatividad. Desde la mirada heteronormada hegemónica, las prácticas sexuales no heterosexuales se consideran perversiones o desviaciones, lo cual ha contribuido a excluirlas, marginalizarlas y rechazarlas.

5 Consideramos 'hitos' a los acontecimientos que generaron una amplia discusión pública y movilizaron políticamente a organizaciones defensoras de los derechos humanos de la diversidad sexual. Además de la publicación y difusión del cuento 'Nicolás tiene dos papás' (2014), podemos incluir el asesinato de Daniel Zamudio (2012), la promulgación de la Ley Antidiscriminación (2012), la promulgación del AUC (2015) y la creciente discusión pública respecto al Matrimonio Igualitario (2016-2017).
} 
socavar lo más profundo de los valores. Según notas de prensa, algunos diputados de la UDI anunciaron la citación de la vicepresidenta ejecutiva de la JUNJI Desireé López de Maturana y del ministro de Educación de la época Nicolás Eyzaguirre a la comisión de familia dado que el ejecutivo patrocina el texto. El argumento de esos grupos indica que el Estado busca imponer el cuento homoparental, frente a lo cual una de las organizaciones impulsoras del cuento, MOVILH, responde que falsean la realidad, por cuanto la lectura del cuento no es obligatoria al estar sujeta a la discusión y a las decisiones de las comunidades educativas.

El MOVILH, como patrocinador del cuento, refuta los planteamientos de esos sectores conservadores. Los califica de homofóbicos al negar la posibilidad de igualdad a la diversidad sexual. Dicha organización sostiene que el cuento contribuye a la discusión acerca de un cambio cultural que promueva los derechos humanos, puesto que muchas personas devalúan y violentan constantemente a los hij@s de parejas del mismo sexo. Esas personas, según dirigentes de la organización, creen que su imposibilidad de comprender la diversidad social es extensiva a toda la sociedad y actúan negando todo lo diferente, sin importarles si con ello dañan a niños y niñas.

La organización Acción Familia, una agrupación de católicos que buscan preservar los principios y tradiciones cristianas de la familia chilena, anunció el inicio de una campaña de recolección de firmas para protestar contra la distribución del cuento. Su director, Juan Antonio Montes, declaró que están haciendo una campaña de sensibilización de la opinión pública contra el respaldo del Ministerio de Educación (MINEDUC) a ese cuento. El dirigente sostiene que la publicación de ese manual es un incentivo para que los niños, a partir de los 4 años, no tengan reparos a las conductas homosexuales. Además, cataloga la publicación del cuento y el respaldo del Estado como una deformación moral de los niños.

En el año 2015 la disputa comienza a escalar debido a que algunas iglesias evangélicas y organizaciones como Comunidad y Justicia (ligada a la UDI) presentaron recursos de protección para impedir la distribución del cuento 'Nicolás tiene dos papás'. Finalmente, la tercera sala de la Corte Suprema fija requisitos al MOVILH para distribuir el cuento. La obra debe ser entregada previo acuerdo y por expresa solicitud de la comunidad educativa. Comunidad y Justicia expresa su conformidad con el fallo, aunque objeta el que no se determine quién fiscalizará al MOVILH. En cuanto a los criterios de elaboración del cuento homoparental y sus aportes pedagógicos, su autora, Leslie Nicholls, señala que se optó por los dos papás y no por dos mamás, pues según estadísticas del MOVILH, de todas las familias homoparentales del país, el $86 \%$ de las parejas lésbicas tiene la tuición legal sobre sus hij@s. Para el caso de los hombres, solo el 33\% de los padres gay, solos o en pareja, tiene la tuición sobre sus hij@s. Los padres gays enfrentan una dificultad adicional y ello justifica el hecho de que el cuento sea protagonizado por dos varones. En cuanto a los aportes, la autora destaca que, pedagógicamente, el cuento es un material educativo para aquellos jardines infantiles, colegios, padres y madres que lo soliciten, fuera de toda imposición. Ese aporte educativo apunta al rol de los padres en la discusión del tema que propone el cuento. La opinión de ellos es fundamental para autorizar la lectura del material. El texto busca que los niños y niñas aprendan desde temprana edad a respetar todas las formas de familia y ver esas diferencias como un valor social que nos hace únicos, declaró Nicholls en 2014.

La controversia que se generó desde el anuncio de la publicación y difusión del cuento homoparental, se expresó en distintos escenarios discursivos como las redes sociales y los racimos de opinión de la ciberprensa tras la publicación de la noticia. 


\section{Referencias teóricas-metodológicas}

\subsection{Estudios críticos del discurso (ECD)}

En este contexto sociopolítico marcado por el problema de la discriminación homofóbica, es necesario revisar algunos planteamientos fundamentales de los Estudios críticos del discurso (ECD) como enfoque interdisciplinario que rastrea el abuso de poder en las prácticas discursivas.

Desde su aparición como área interdisciplinaria generada desde los Estudios del Discurso, los ECD (Berardi, 2005; Fairclough, 2013; Fairclough \& Wodak, 2001; Pardo, 2007; Van Dijk, 2009) proponen examinar las prácticas discursivas desde la perspectiva de la dominación y el abuso de poder. Los grupos hegemónicos, amparados en una trama institucional (Fairclough, 2013), difunden determinadas configuraciones acerca del mundo social hacia los grupos que tienen acceso limitado tanto a las prácticas discursivas como a su difusión. En el caso del problema de la discriminación homofóbica, esos grupos dominantes se sitúan en una posición heteronormativa dominante que busca invisibilizar las sexualidades desobedientes o no heteronormativas (De Abreu, 2014) expresadas por discursos de resistencia (Chilton \& Schäffner, 2001).

Las concepciones ideológicas heteronormadas respecto a la sexualidad, amparadas en tramas institucionales, han contribuido a excluir y marginalizar otras formas de experimentar la sexualidad. Además, esas concepciones ideológicas han impactado las relaciones de poder entre las personas según su orientación sexual e identidad de género. Según Pollak (1987), en general, las dos grandes visiones que determinan a la categoría 'homosexual' son las que, primero, conciben la heterosexualidad como norma absoluta $\mathrm{y}$, segundo, las que consideran a todas las manifestaciones sexuales en un mismo nivel. La primera visión, la heteronormativa, postula que los comportamientos no heterosexuales son desviaciones o perversiones; mientras que la segunda, plantea que esos comportamientos son simplemente diferentes y no están organizados jerárquicamente. Así, las concepciones heteronormadas sobre la homosexualidad han validado la condena, el desprecio y también la muerte.

Además, la necesidad de investigar el problema social de la discriminación hacia la diversidad sexual, se explica a partir de las luchas políticas que esos grupos han desplegado durante gran parte del siglo XX y que germinaron en la segunda mitad del siglo XIX (Zubiaur, 2007). Las diversas organizaciones pro diversidad sexual, en distintos lugares del mundo, han visibilizado el problema de la discriminación que los afecta y han logrado instalarlo como un problema de derechos humanos. En tanto problema de derechos humanos, se inscribe en el ámbito de la discusión política, lo cual resulta particularmente sensible, pues el tratamiento institucional hacia la diversidad sexual se ha transformado en un parámetro clave para evaluar el estado de las democracias modernas en el contexto de la revolución global gay descrita por Martel (2013). Dicha revolución ha problematizado no solo el tratamiento hacia la comunidad gay, sino también las identidades sexuales y sociales tanto de los grupos sexuales hegemónicos como de la propia disidencia sexual.

Desde la perspectiva de Fairclough (2014), el discurso es una práctica social que, semióticamente, construye aspectos del mundo físico, mental o social. Fairclough (2013, 2014) refuerza la relevancia de una perspectiva crítica lingüísticamente orientada, al señalar que en las 
sociedades contemporáneas se requiere alcanzar adecuados niveles de bienestar. La dimensión crítica de los estudios del discurso es una forma de aportar en el mejoramiento de las realidades sociales para alcanzar justicia y mejorar el bienestar de las personas al poner atención en el discurso y su relación con aspectos sociales como las relaciones de poder, ideologías, instituciones e identidades sociales (Fairclough, 2014).

Desde el punto de vista conceptual, este estudio busca examinar las representaciones discursivas referidas a la comunidad gay desde la perspectiva del lenguaje evaluativo y mostrar cómo esas representaciones discursivas revelan creencias articuladas a lo largo de la historia.

\subsection{Representaciones discursivas}

La cognición social indica que los modelos de pensamiento o visiones acerca de categorías sociales son generadas, reforzadas y validadas por los media y las plataformas de la red, lo que apoya la construcción del conocimiento social. Las representaciones sociales (Morales, 1994; Moscovici, 1993; Myers, 2001) corresponden a la elaboración de un concepto acerca de las categorías sociales desde la inducción social. Ellas constituyen un sistema de referencias que permite interpretar lo que sucede en nuestro entorno y explicar comportamientos discursivos discriminatorios.

En este sentido, el discurso es el instrumento a través del cual se expresan esas representaciones, pero -a la vez- las constituye (Pardo, 1999). De ahí que se emplee el término representaciones discursivas. Estas corresponden a las creencias que se construyen semióticamente, esto es, por medio de recursos léxicos, semánticos, sintácticos y/o multimodales (Vasilachis de Gialdino, 2003) y que son difundidas posteriormente a través de diversas prácticas sociales.

En este sentido, el sistema de VALORACIÓN, al establecer las evaluaciones intersubjetivas de los hablantes/escritores, puede contribuir a mostrar formas de representación de diversos aspectos del mundo social. El sistema de VALORACIÓN podría contribuir a evidenciar formas de representación de actores sociales como la comunidad gay, organizaciones de diversidad sexual o líderes de esas organizaciones; eventos como la publicación y difusión del cuento homoparental 'Nicolás tiene dos papás' y el objeto, es decir, el cuento propiamente tal. Los significados interpersonales valorativos acerca del mundo social podrían proyectar creencias y visiones acerca de ese mundo social configurado en los textos.

Las representaciones discursivas que se proyectan en los textos construyen, a través de diversos recursos lingüísticos, imágenes sociales al reflejar formas de tratamiento hacia los grupos sociales a los cuales alude. Por ello, el lenguaje evaluativo empleado en los textos respecto a grupos humanos o diversos aspectos asociados a ellos resulta clave en este estudio.

Para los efectos de determinar las representaciones discursivas acerca de la comunidad gay, se empleará el dispositivo teórico-metodológico ofrecido por el modelo de VALORACIÓN (Hood, 2010; Kaplan, 2004; Martin, 2003; Martin y White, 2005; Oteíza y Pinuer, 2012; White, 1999) que se inserta dentro de un marco analítico más amplio: la LSF. Esta, en general, concibe al lenguaje como un sistema sociosemiótico estratificado desde el cual los hablantes/escritores toman opciones de construcción de significados desde un paradigma de posibilidades de significación, de acuerdo con el contexto social y cultural.

\subsection{Aspectos generales sobre el modelo de VALORACIÓN}


El modelo de VALORACIÓN profundiza en la metafunción interpersonal del lenguaje y se realiza en el estrato semántico-discursivo de la configuración sociosemiótica estratificada desarrollada por la LSF. Con una fuerte influencia del Dialogismo de Bajtín (ver White, 2010) y el Interaccionismo Social de Volóshinov (1973), el modelo de VALORACIÓN plantea que los hablantes utilizan el lenguaje para evaluar comportamientos, situaciones o experiencias. Se ocupa de las expresiones lingüísticas que expresan una valoración, una actitud o una emoción o de los recursos lingüísticos que posicionan de forma interpersonal a hablantes y/o escritores. Explica cómo el hablante se compromete con sus enunciados y los ajenos.

El modelo de VALORACIÓN ubica los recursos evaluativos en tres dimensiones semánticas: ACTITUD, GRADACIÓN y COMPROMISO (Martin y White, 2005). La ACTITUD alude a los valores que los hablantes expresan en sus juicios o intervenciones afectivas o emocionales. Incluye JUICIO (evaluación del comportamiento humano de acuerdo a las normas sociales), AFECTO (caracterización de las situaciones de acuerdo a la emoción) y APRECIACIÓN (evaluación a partir de juicios estéticos) (Martin y White, 2005). La GRADACIÓN apunta a los valores a través de los cuales los hablantes aumentan o disminuyen el impacto interpersonal o la fuerza de sus emisiones. Implica desdibujar o agudizar sus categorías semánticas. Se le denomina "semántica a escala" e incorpora la fuerza (intensificadores, potenciadores o enfatizadores) y foco (evasivas o ambigüedad) (White, 1999). El COMPROMISO se refiere a los recursos lingüísticos usados para posicionar al hablante respecto a propuestas de otros, o sea, cómo el hablante se hace cargo de la diversidad de puntos de vista, reconociéndolos o ignorándolos (White, 1999, Martin y White, 2005).

El sistema de VALORACIÓN es un aparato teórico y metodológico funcional a los ECD, pues permite revelar las representaciones discursivas producidas y difundidas por los discursos (mediáticos, en este caso) al reflejar los posicionamientos ideológicos de hablantes/escritores respecto al mundo social.

El sistema de VALORACIÓN y sus subsistemas se ilustran de manera esquemática en la siguiente figura:

Figura 1. Esquema general del modelo de Valoración (Appraisal) según Martin y Rose 2007 y Martin y White 2005 (tomado de Oteíza, 2009).

\begin{tabular}{|c|c|c|}
\hline \multirow{7}{*}{$\begin{array}{l}\text { Valoración } \\
\text { (Appraisal) }\end{array}$} & \multirow{3}{*}{ Actitud } & $\begin{array}{l}\text { Afecto: In/Felicidad, In/Seguridad, } \\
\text { In/Satisfacción. }\end{array}$ \\
\hline & & Juicio: Estima y Sanción Social. \\
\hline & & $\begin{array}{l}\text { Apreciación: Reacción, Composición y } \\
\text { Valoración Social. }\end{array}$ \\
\hline & \multirow{2}{*}{ Gradación } & Fuerza: Elevar o bajar. \\
\hline & & Foco: Agudizar o precisar. \\
\hline & \multirow[b]{2}{*}{ Compromiso } & $\begin{array}{l}\text { Monoglosia (No se reconocen posiciones } \\
\text { alternativas). }\end{array}$ \\
\hline & & $\begin{array}{l}\text { Heteroglosia (Reconocimiento de } \\
\text { posiciones alternativas). }\end{array}$ \\
\hline
\end{tabular}

Este modelo corresponde a una extensión de la metafunción interpersonal propuesta por la LSF. La VALORACIÓN opera a nivel discursivo-semántico por acumulación en una prosodia valorativa que se va desplegando a lo largo del texto, pero donde resulta clave el trabajo analítico 
en el nivel léxico-gramatical, si se considera que cada estrato se realiza en el inferior en una relación de metarredundancia (Halliday \& Matthiessen, 2014; Lemke, 1995).

En síntesis, la perspectiva de los ECD nos permitirá develar las relaciones de poder que se configuran en los comentarios de ciberprensa a través de los recursos valorativos desplegados en los textos. Además, esos recursos valorativos empleados en los comentarios darán cuenta de creencias y visiones respecto del mundo social. De esta manera, la trayectoria analítica que se despliega en este estudio se inicia en el nivel descriptivo de las categorías analíticas valorativas, para desde ahí interpretar los significados interpersonales subyacentes en cuanto a las relaciones de poder que se articulan en los textos y las creencias y visiones respecto al mundo social.

\section{Metodología}

Situarse metodológicamente en el paradigma cualitativo, implica intentar responder el cómo y por qué de los fenómenos sociales. En este sentido, proporciona un conocimiento vinculado a la interpretación y explicación de los problemas sociales (Vasilachis de Gialdino, 2012). El recorrido analítico que nos proponen los ECD (Fairclough, 2013) contempla inicialmente el abordaje descriptivo a nivel textual en el que será clave el modelo de VALORACIón y sus categorías analíticas, para desde ahí acceder a niveles interpretativos (Guba \& Lincoln, 1994).

Para cumplir los objetivos antes señalados, el análisis se centrará en el complejo clausular contenido en los comentarios. Cabe precisar que el modelo de VALORACIÓN opera en el nivel semántico-discursivo de la estratificación y si en este trabajo se enfoca en los complejos clausulares es únicamente para facilitar el avance del análisis. Los textos se van organizando en la siguiente matriz:

Figura 2. Matriz de análisis (elaboración propia, basada en Martin y White, 2005, y Oteiza, 2009).

\section{Matriz de análisis \\ SISTEMA DE VALORACIÓN}

\begin{tabular}{|l|l|l|l|l|}
$\begin{array}{l}\text { ¿Qué y quiénes } \\
\text { Son evaluados? } \\
\text { Entidades } \\
\text { discursivas }\end{array}$ & $\begin{array}{l}\text { Sistema } \\
\text { semántico de } \\
\text { ACTITUD: }\end{array}$ & $\begin{array}{l}\text { Sistema de } \\
\text { COMPROMISO: }\end{array}$ & $\begin{array}{l}\text { Sistema de } \\
\text { GRADACIÓN } \\
\text { de las } \\
\text { valoraciones: }\end{array}$ \\
$\begin{array}{l}\text { Actores/Procesos/ } \\
\text { Eventos/ } \\
\text { Cosas }\end{array}$ & Discurso Analizado & $\begin{array}{l}\text { Afecto } \\
\text { Juicio } \\
\text { Apreciación }\end{array}$ & $\begin{array}{l}\text { Heteroglosia } \\
\text { Monoglosia }\end{array}$ & \\
& & Fuerza \\
\end{tabular}

La orientación analítica se focaliza en la comunidad gay, la noticia de la publicación y difusión del cuento y el cuento. De este modo entonces, nos interesa evidenciar cómo se construyen los significados valorativos en relación con los actores sociales, el evento y el objeto en tanto entidades discursivas. 
En el apartado siguiente se exponen once ejemplos extraídos del corpus obtenido de los ciberperiódicos examinados. Dichos ejemplos se organizan por entidad discursiva evaluada, esto es, comunidad gay, difusión del cuento y el cuento y su contenido. De estos ejemplos examinados desde los sistemas de VALORACIÓN, ocho de ellos corresponden a evaluaciones de la comunidad gay y tres se refieren al cuento homoparental. La totalidad del análisis del corpus tomado para este estudio se puede consultar en los anexos de este documento.

\section{Análisis y resultados}

A continuación se examinan algunos ejemplos extraídos del análisis (Ver anexos análisis completo) que permiten evidenciar las valoraciones referidas a las entidades discursivas antes señaladas.

\subsection{Análisis valorativo de los gay}

En cuanto a las valoraciones referidas a la comunidad gay, se exponen los siguientes casos:

\section{Emol.com}

Ejemplo 1

Pero estos maricones (en el amplio sentido)

quieren que mi hija empiece a preguntar antes de tiempo.

El análisis de este ejemplo -que corresponde a emol.com- muestra, desde el punto de vista del sistema de ACTITUD, el subsistema JUICIO de sanción social de integridad que cuestiona moralmente el comportamiento de quienes están detrás del cuento y su difusión. Destaca la evocación a la comunidad gay a través de la expresión "maricones".

A su vez se aprecia la ACTITUD de AFECTO a nivel de inclinación que corresponde a un irrealis pues implica un deseo -según el hablante- de que los homosexuales buscan anticipar las conversaciones sobre sexualidad entre los niños y sus padres y que se expresa lingüísticamente en el proceso mental "querer".

Desde el punto de vista del COMPROMISO, se evidencia un COMPROMISO heteroglósico de contracción dialógica que opera a nivel de contraexpectativa expresada en la partícula adversativa "pero".

En el ámbito de la GRADACIÓN, se aprecia su subsistema foco en "amplio sentido", pues se desdibuja la noción de sentido y también fuerza por intensificación de extensión temporal en "antes de tiempo". En el primer caso, se atenúa el sentido de la expresión "maricones" al no referirse exclusivamente a quienes son homosexuales. En el caso de "antes de tiempo" se formula una crítica graduada a adelantar las inquietudes de los niños en torno a la sexualidad.

\section{Ejemplo 2}

$\underline{\text { no permitamos que el movilh y los degenerados de este país se salgan con la suya }}$,

Es claro, en el ejemplo anterior, el JUICIO de sanción social que incorpora una valoración moral negativa como se aprecia en la expresión "degenerados". Además el JUICIO evocado "se salgan 
con la suya" involucra una crítica a una supuesta obstinación de los homosexuales por impulsar determinadas iniciativas favorables a la inclusión.

Desde el punto de vista del COMPROMISO, se aprecia un intento por atacar discursivamente las iniciativas que surgen del movimiento gay a través de expresiones como "(nosotros) no permitamos, destruyamos y defendamos". Se hace un llamado a no permitir que el MOVILH impulse determinadas iniciativas, a la destrucción del cuento homoparental y a la defensa de supuestos valores heterosexuales.

Por su parte, en el caso del sistema de GRADACIÓn, se aprecia el subsistema foco con intención de agudizar la significación de los valores representados por la heteronorma en "verdaderos valores".

Ejemplo 3

Eso es todo. Dejen de vulnerar los derechos de los niños...

En este ejemplo, el hablante evalúa a quienes defienden y difunden el cuento homoparental. Esos actores sociales son valorados a través de JUICIO de sanción social de integridad inscrita (dejen de vulnerar), pues desde la perspectiva del comentarista, el comportamiento asumido por quienes respaldan el cuento atenta contra los derechos de los niñ@s, por lo que resulta objetable desde el punto de vista moral. Desde la mirada del COMPROMISO se reconocen enunciados heteroglósicos con contracción dialógica de pronunciamiento lo que significa que el hablante reconoce otra voz y hace un llamado implícito de atención a un "ustedes" para terminar con ese comportamiento considerado perjudicial para los niños. Desde la mirada que nos ofrece la GRADACIÓn, "eso es todo" corresponde a un intensificador de fuerza que resalta la aparente ausencia de polémica, pues según el comentarista, "la naturaleza dice hombre y mujer forman y dan vida".

\section{Ejemplo 4}

Como vamos a enchufarles una cosa q es más difícil,chocante y poco normal...

JUICIO de estima social negativo de normalidad, expresado de manera inscrita, es lo que se puede advertir en el caso anterior. La secuencia de adjetivos empleados por el comentarista se refiere a las relaciones homoparentales como algo que escapa a la normalidad de lo social y culturalmente establecido. Esto además explica las razones de "como (nosotros) vamos a enchufarles eso", es decir, cómo van a explicar a los niños aquello tan chocante, difícil y poco normal. Esto último corresponde a un enunciado heteroglósico que recoge otras posiciones a través de la contracción dialógica, advirtiéndose una especie de refutación respecto a lo que piensan quienes promueven el cuento: organizaciones gay.

Desde la gradación se advierten dos recursos: uno de intensificación como "más difícil" y otro de cuantificación como "poco normal" que apunta directamente a la anormalidad y en este sentido podría funcionar como atenuador de la categoría 'normal'.

latercera.com

Ejemplo 5

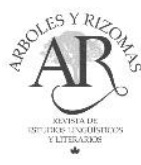


puedo entender que algunos nacen con esa condicion y tolerarlos ....pero de ahi a PROMOVER la homosexualidad como un estilo de vida u opcion sexual, eso es una ABERRACION de la sociedad actual

En este ejemplo, al mencionar a los homosexuales, el hablante emplea un recurso de GRADACIÓN de cuantificación para referirse a que no todos los homosexuales nacen con esa condición. Incluso a través de JUICIO de estima social evocado los considera normales al expresar que "algunos nacen con esa condición" y por tanto "los tolera". Sin embargo, el hablante no acepta que los homosexuales "promuevan" la homosexualidad como si esta fuera una ideología, expresada en "un estilo de vida" y considerándola una opción que las personas pueden elegir. Ese juicio de sanción social de integridad inscrito en la expresión "ABERRACIÓN" con la que define la homosexualidad alude a la acción de 'PROMOVER' esa condición sexual y confirma una evaluación negativa de los homosexuales y la homosexualidad, basada en consideraciones de tipo moral. En este ejemplo subyacen dos concepciones respecto a la homosexualidad. Algunos nacen y otros se convierten a partir de su promoción.

Se advierte un COMPROMISO heteroglósico en la utilización de la perífrasis verbal de carácter mental "puedo entender" que deja entrever una aceptación de ciertos homosexuales (los que nacen con esa condición) y de este modo "los tolera". Respecto del verbo tolerar, consideramos necesario precisar que semánticamente nos indica que algo nos molesta, pero es aceptado.

Desde el punto de vista de la tipografía, conviene aclarar que la utilización de mayúsculas en el caso del proceso "promover" sugiere un grito, un llamado de atención de rechazo a esta según el hablante- verdadera ideología que es la homosexualidad y que los homosexuales se empeñan en difundir e inculcaren 1@s niñ@s.

\section{Ejemplo 6}

el MOVILH esta haciendo PROSELITISMO ${ }^{6}$ contra los heterosexuales.......

En este caso "hacer proselitismo" corresponde a una acción malintencionada, reprochable para el hablante, sobre todo porque lo considera un ataque contra los heterosexuales. Además, si nos atenemos al significado que propone la RAE de la expresión "proselitismo", se le confiere a la homosexualidad un carácter de religión o de doctrina política.

En el plano del COMPROMISO, se aprecia heteroglosia de contracción dialógica dado que se expresa un reconocimiento de las voces de los homosexuales a las que se le atribuyen supuestas intenciones contra los heterosexuales. Con esto se expresa discursivamente la dualidad "nosotros" (heterosexuales) y "ellos" (homosexuales) y una lucha ideológica en la que están siendo víctimas los heterosexuales. Esa lucha ideológica se plantea a través de la creencia 'tu beneficio (captar adeptos) es mi perjuicio'. Esto significa que garantizar derechos a la comunidad gay implica sustraer derechos a las personas heterosexuales. Al hablar de 'proselitismo' se está considerando la homosexualidad como una doctrina.

\section{Ejemplo 7}

acaso ellos y sus relaciones sexuales no son naturales y creen saber mas que Dios en cuanto a la vida de las personas, pregunto yo.

${ }^{6}$ DRAE plantea que el significado de proselitismo es "celo por captar prosélitos". Prosélitos correspondería a personas incorporadas a una religión o a partidarios que se ganan para una facción o doctrina.

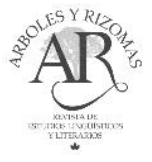


Como en casos anteriores, en este ejemplo, se expresa de forma inscrita JUICIO de estima social negativo, al referirse a las relaciones sexuales homosexuales. Se aprecia, además, heteroglosia de contracción dialógica en el enunciado del comentarista al referirse a lo que los homosexuales supuestamente creen (saber más que Dios). Desde la semántica a escala, advertimos un recurso de FUERZA por intensificación en "creen saber más que Dios" para resaltar una supuesta soberbia de la comunidad gay frente al poder divino.

\section{Ejemplo 8}

Dios no creo homosexuales, lesbianas, solo es una distorsión de la mente humana que hoy en día que hoy en día la sociedad $\underline{\text { aprueba }}$

Al igual que en caso anterior, en este ejemplo podemos observar el recurso del JUICIO negativo de estima social de normalidad, inscrita en el ítem léxico "distorsión". Además, a través de una cláusula declarativa material negativa se expresa una monoglosia, en tanto, no se da cabida a posicionamientos alternativos, sino que se expresa una declaración no susceptible de discutir, asumida como dada "Dios no creo homosexuales, lesbianas, solo es una distorsión de la mente (...)". Además de considerar que la homosexualidad escapa a la normalidad, el hablante plantea una evaluación negativa de la sociedad que da cabida a esos comportamientos anormales, y lo hace mediante el recurso del JUICIO negativo de sanción social de integridad, pues se considera que 'aprobar' esas conductas atenta contra valores morales.

\subsection{Análisis valorativo del cuento y su difusión}

Emol.com

Ejemplo 9

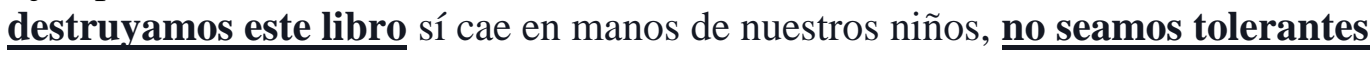

En el ejemplo precedente podemos observar el subsistema de APRECIACIÓN (valuación) de manera inscrita por cuanto se considera el cuento homoparental como dañino para los niños y por eso se hace un llamado a 'destruirlo' y a 'no ser tolerantes' con él. Desde la mirada del COMPROMISO se reconoce heteroglosia de contracción dialógica a nivel de pronunciamiento que se inscribe en la alusión a la primera persona del plural (nosotros) asociada a los procesos "no permitir", "destruir" y "defender" (ver con mayor detalle en los anexos). Este último proceso, 'defender', se refiere a los supuestos verdaderos y únicos valores heterosexuales que -según el hablante- "deben tener" los hombres del futuro. Así se valida la heteronorma y con ello se devalúan y excluyen sexualidades no heterosexuales.

\section{Ejemplo 10}

Creo q no es el camino ni la forma de que que sean incluidos.

En este ejemplo observamos una evaluación evocada del cuento y su difusión, a través de APRECIACIÓN (valuación) en la expresión "no es el camino ni la forma". El cuento, su contenido y su difusión no son reconocidos como válidos como forma de inclusión de grupos de personas que 
son tradicionalmente discriminadas, ni tampoco como un recurso educativo valioso en términos de contribución al respeto por las sexualidades diferentes a la normada.

Por su parte, el COMPROMISO heteroglósico se advierte en el reconocimiento de un "ellos": los que se intenta incluir, los homosexuales. Nuevamente desde el lenguaje expresado en los comentarios se advierte la presencia de una voz heterosexual que es la que tiene que incluir y, por otra parte, una voz homosexual que lucha por la inclusión y el respeto.

\section{Latercera.com}

Ejemplo 11

\section{Esto es una PATRAña ${ }^{7}$}

Tipográficamente, salta a la vista en este ejemplo el uso de mayúscula en "PATRAÑA" cuestión que, como ya se indicó más arriba, es característico del discurso del chat y las redes sociales para indicar grito o llamar la atención.

En términos valorativos, se califica al cuento homoparental como una 'patraña', es decir, como una invención destinada al engaño, expresando de este modo una APRECIACIÓN a nivel de valuación aunque no se refiere al cuento en términos estéticos, sino más bien como moralmente reprochable -inferimos- por su contenido. Con este intento de descalificar el cuento y su contenido desde el punto de vista moral, desde una perspectiva heteroglósica, se busca refutar opiniones y creencias acerca del mundo social configurado en el cuento homoparental. En este mundo social relevado en el cuento, tienen cabida formas de experimentar la sexualidad y la vida afectiva que difieren de las concepciones heteronormativas.

\section{Conclusiones y discusión final}

A través del análisis global de los comentarios de ciberprensa y de los ejemplos examinados que dan cuenta de formas de representación discursivas de la comunidad gay, la publicación y difusión del cuento homoparental y del cuento; se puede concluir que de forma mayoritaria se evalúa negativamente las tres entidades discursivas señaladas.

En el caso de las referencias a la comunidad gay se evidencian valoraciones negativas de JUICIO de sanción social y estima social asociadas a inmoralidad y anormalidad en los comentarios de ambos ciberperiódicos. A su vez y, desde la perspectiva del COMPROMISO, se aprecia en general una tendencia a recoger las posiciones defendidas por la comunidad gay a través de la contracción dialógica preferentemente. Se refutan dichas posiciones aludiendo a argumentos basados en aparentes verdades indiscutibles que a su vez se amparan en mandatos divinos y concepciones heteronormativas históricamente instaladas. En los casos de monoglosia se observan cláusulas declarativas relacionales y materiales fundadas en una argumentación religiosa que no deja espacio para otras posiciones. Con esto se invisibilizan las voces de las sexualidades alternativas no heterosexuales.

En el caso de la publicación y difusión del cuento homoparental ocurre algo similar. Las valoraciones son negativas y apelan a una supuesta confusión y alteración de los valores tradicionales que dicha publicación y difusión estaría promoviendo en los niños. Se advierten en

\footnotetext{
${ }^{7}$ Una de las acepciones propuestas por en el DRAE de la palabra 'patraña' la define como una 'invención creada con
} el propósito de engañar'. 
el sistema de ACTITUD valoraciones negativas de APRECIACIÓN en cuanto a valuación y JUICIOS de sanción y estima sociales para quienes están detrás del evento (organizaciones de diversidad sexual e instituciones académicas). Los recursos valorativos recién mencionados expresan una visión de la homosexualidad que la homologa a una doctrina que se busca difundir y que erosionaría o pondría en peligro los derechos de las personas heterosexuales.

El cuento en sí es evaluado negativamente en términos del tema que desarrolla (familia homoparental). Se destacan las evaluaciones negativas asociadas a aberraciones o distorsiones de la normalidad y la tradición heteronormativa. Se advierte a través del recurso valorativo de JUICIO, un intento -primero- por menoscabar las relaciones homosexuales al vincularlas a la intención de socavar la heteronormatividad y, a continuación, devaluar a la familia homoparental. Desde las valoraciones subyace la idea de que solo en las relaciones heterosexuales yace la moralidad, la naturaleza y la normalidad. Conviene destacar que respecto del cuento propiamente tal no se emiten evaluaciones de naturaleza estética, sino que solo se refieren a su contenido: las relaciones homoparentales.

En cuanto a la prosodia valorativa, podemos decir que la naturaleza del género discursivo no permite elaborar una mirada global de las valoraciones, pues los textos emergen de forma fragmentada y, además, fueron tomados de manera aleatoria. Con esto se vislumbra un desafío metodológico para futuros estudios en cuanto a que quizás los análisis de comentarios de ciberprensa pudieran desarrollarse a través de otros recursos para así incluir la totalidad de los comentarios y de este modo poder mirar las eventuales fluctuaciones valorativas de los racimos de comentarios. En este estudio solo se construyó un corpus parcial de ambos ciberperiódicos.

Un corpus más amplio podría ofrecer más contundente evidencia de cómo se articula la discriminación hacia la comunidad gay en comentarios de ciberprensa y en otros géneros discursivos. Al parecer los avances institucionales van más adelante que las mentalidades de la población chilena -de acuerdo a lo que arroja el análisis en este trabajo- por lo que la homofobia como expresión del odio a las sexualidades disidentes mantiene una presencia importante en los medios de comunicación y ello justifica nuevas aproximaciones al problema social de la discriminación.

Los recursos lingüísticos valorativos empleados en los textos dan cuenta de ciertas creencias muy arraigadas en la sociedad chilena respecto a la comunidad gay y las relaciones gays. En este sentido, este estudio confirma la existencia de una homofobia latente denunciada en otra estudios como los de Farías (2015) y Farías y Clavijo (2017) en los que se informa acerca de los recursos sociosemióticos que construyen el discurso homofóbico en el paisaje urbano de Santiago de Chile y Bogotá, Colombia; y el estudio de Guerrero y Müller (2012) que rastrea las valoraciones en torno a la discriminación de género en textos informativos, a propósito del caso del asesinato de Daniel Zamudio ocurrido en marzo de 2012 y la discusión en torno a la Ley Antidiscriminación producida durante ese mismo año.

Los resultados se alinean con las concepciones condenatorias acerca de la comunidad gay que han sido construidas, validadas y difundidas a lo largo de la historia a través de tramas institucionales hegemónicas (Gramsci, 1978). En ese entramado ideológico han tenido relevancia los discursos religiosos, médicos y jurídicos (Asalazar, 2017; Contardo, 2011; Cornejo, 2007, 2009; Fone, 2008; Zubiaur, 2007). Desde la heteronorma construida por la trama institucional se configura la categoría gay como sujeto peligroso y carente de derechos. Ese peligro asociado al sujeto gay, se basa en que este desafía la norma y erosiona los derechos de las personas heterosexuales. Esa peligrosidad, además, se ampara en la concepción de la homosexualidad como una doctrina que busca la conversión de los sujetos. 
El análisis y los ejemplos presentados muestran los recursos lingüísticos valorativos que canalizan, por una parte, la discriminación homofóbica y, por otra, la validación de las relaciones heteronormadas como únicas posibles. Con esto último emerge la tradicional contraposición entre "nosotros" (heterosexuales) y "los otros" (homosexuales) y con ella las estrategias de discurso político de legitimación y deslegitimación (Chilton \& Schäffner, 2001). Se reconocen valores en nosotros, por un lado, y por otro, aberraciones y anormalidades reprochables, incluso moralmente, en "los otros", la comunidad gay y sus formas de visibilización y representación dentro del mundo social configurado en los textos de ciberprensa analizados.

En síntesis, el estudio del corpus muestra evidencia lingǘstica que construye representaciones discursivas acerca de la comunidad gay, la publicación y difusión del cuento y el cuento, en las que -en general- subyace una ideología conservadora basada en concepciones tradicionales respecto al ejercicio de la sexualidad y la afectividad que se sintetizan en el concepto de heteronorma como reguladora y punto de referencia de lo natural, normal y decente.

\section{Bibliografía}

Asalazar, G. (2017). Deseo invisible. Santiago cola antes del golpe. Santiago, Chile: Cuarto Propio.

Berardi, L. (Ed.). (2005). Análisis crítico del discurso: perspectivas latinoamericanas. Santiago, Chile: Frasis.

Chilton, P. \& Schäffner, C. (2001). Discurso y Política. En T. Van Dijk. (Comp.). El Discurso como interacción Social (pp. 297-329). Barcelona: Gedisa.

Cornejo, J. (2007). La homosexualidad como una construcción ideológica. Límite. Revista de Filosofía y Psicología 16, 83-108.

Cornejo, J. (2009). Equívocos del lenguaje: homoerotismo en lugar de homosexualidad. Alpha $29,143-154$.

https://doi.org/10.4067/s0718-22012009002900010

Contardo, O. (2011). Raro. Una historia gay de Chile. Santiago: Planeta.

De Abreu, C. L. (2014). Géneros y sexualidades no heteronormativas en las redes sociales digitales. Tesis Doctoral. Universidad de Barcelona. Facultad de Bellas Artes. Barcelona.

DRAE. (2014). 23 Edición)

Fairclough, N. \& Wodak, R. (2001). Análisis crítico del discurso. En T. Van Dijk, (Comp.), El Discurso como interacción Social (pp. 327-404). Barcelona: Gedisa.

Fairclough, N. (2013). Critical discourse analysis. The critical study of language. New York: Routledge.

Fairclough, N. (2014). Critical discourse analysis. En J. P. Gee and M.Handford (Eds.) The Routledge Handbook of Discourse Analysis (pp. 9-20). Abingdon: Routledge.

https://doi.org/10.4324/9780203809068.ch1

Farías, M. (2015). Análisis crítico multimodal y percepción del discurso homofóbico en el paisaje sociosemiótico de Santiago de Chile. En D. Garcia da Silva y M.L. Pardo. (Comps.) Pasado, Presente y Futuro de los Estudios del Discurso en América Latina. Libro Homenaje a los 20 años de la Asociación Latinoamericana de estudios del discurso (ALED). (pp. 159-171). Brasilia: Universidad de Brasilia.

https://doi.org/10.35956/v.18.n2.2018.p.6-22

Farías, M. \& Clavijo, A. (2017). Análisis exploratorio de discurso homofóbico multimodal en Santiago de Chile y Bogotá. Discurso y Sociedad 11(1) 47-69.

Fluxá, R. (2014). Solos en la noche. Zamudio y sus asesinos. Santiago de Chile: Catalonia. 
Claudio Araya Seguel

Fone, B. (2008). Homofobia. Una historia. México: Océano.

Gramsci, A. (1978). Los intelectuales y la organización de la cultura. México: Juan Pablos Editor.

Guba, E. G. \& Lincoln Y. S. (1994). Competing Paradigms in Qualitative Research. En N.K.

Denzin, N.K. \& Y.S. Lincoln (Eds). The Handbook of Qualitative Research (pp.105-117).

Thousand Oaks, CA: Sage.

https://doi.org/10.1177/1094428109332198

Guerrero, S. \& Müller, V. (2012). Una aproximación a las valoraciones en torno a la discriminación de género en tres medios de la prensa chilena. Boletín de Filología, 47(2), 71-99.

https://doi.org/10.4067/s0718-93032012000200003

Halliday, M. A. K. \& Matthiessen, C. (2014). An introduction to functional grammar. New York, NY: Oxford University Press.

Hood, S. (2010). Appraising Research: Evaluation in Academic Writing. New York, NY: Palgrave Macmillan.

Kaplan, N. (2004). Nuevos desarrollos en el estudio de la evaluación en el lenguaje: la teoría de la valoración. Boletín de Lingüística, 22, 52-78.

https://doi.org/10.22201/dgpfe.9786070268403e.2015

Lemke, J. (1995). Intertextuality and text semantics. En P. H. Fries y M. Gregory (Eds.), Discourse in society: systemic functional perspective. (pp. 85-144). Norwood, NJ: Ablex.

Martel, F. (2013). Global gay. Cómo la revolución gay está cambiando el mundo. México: Taurus.

Martin, J. (2003). Introduction. Text 23(2), 171-181.

Martin, J. \& Rose, D. (2007). Working with the discourse. Meaning beyond the clause. London, NY: Continuum.

Martin J. \& White, P. (2005). The language of Evaluation. Appraisal in English. New York: Palgrave Macmillan.

Morales, J. F (1994). Introducción a la Sicología Social. Barcelona: Ariel.

Moscovici, S. (1993). Sicología Social II. Barcelona: Paidós.

Movilh (2014). Nicolás tiene dos papás. Santiago de Chile: Autor

Myers, D. (2001). Sicología Social. Bogotá: McGrawhill.

Newton, E. (1972). Mother Camp: Female Impersonators in America. Chicago: University of Chicago.

Núñez Noriega, G. (2015). Sexo entre varones. Poder y resistencia en el campo sexual. México: UNAM. Instituto de Investigaciones Sociales.

Oteíza, T. (2009). Solidaridad ideológica en el discurso de la historia: Tensión entre orientaciones monoglósicas y heteroglósicas. Signos, 42(70), 219-244.

https://doi.org/10.4067/s0718-09342009000200004

Oteíza, T. \& Pinuer, C. (2012). Prosodia valorativa: construcción de eventos y procesos en el discurso de la historia. Discurso y Sociedad, 6(2), 418-446.

Pardo, N. (2007). Cómo hacer un análisis crítico del discurso: Una perspectiva latinoamericana. Santiago: Frasis.

Pardo, N. (1999). Análisis crítico del discurso: un acercamiento a las representaciones sociales. Forma y Función, 12, 63-81.

Pollak, M. (1987). La Homosexualidad Masculina o ¿La Felicidad en el Ghetto? En Sexualités occidentales. Ph. Ariès, A. Béjin, M. Foucault y otros. Paidós: Buenos Aires. 71-102.

Sontag, S. (1984). En Contra la interpretación y otros ensayos. Barcelona: Seix Barral.

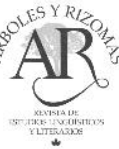


Claudio Araya Seguel

Van Dijk, T. (2009). Discurso y poder. Contribuciones a los estudios críticos del discurso. Barcelona: Gedisa.

Vasilachis de Gialdino, I. (2003). Pobres, pobreza, identidad y representaciones sociales. Barcelona: Gedisa.

Vasilachis de Gialdino, I. (2012). De la forma de conocer a las formas de conocer. En NK Denzin \& YS Lincoln (Comps.). Manual de investigación cualitativa, 2. Paradigmas y perspectivas en disputa (pp. 1-10). Barcelona: Gedisa.

Volóshinov, V. I. (1973). Marxism and the philosophy of language. Nueva York, NY: Seminar Press.

White, P. (1999). Un recorrido por la teoría de la valoración [en línea]. Disponible en: http://www.grammatics.com/appraisal/SpanishTranslation-AppraisalOutline.pdf

White, P. (2010). Taking Bakhtin seriously: dialogic effect in written, mass communicative discourse. Japanese Journal of Pragmatics, 12, 37-53.

Zubiaur, I. (2007). Pioneros de lo homosexual. Barcelona: Anthropos.

\section{Anexos}

Anexo I. Emol.com

\section{EMOL.com}

Cuento "Nicolás tiene dos papás" podrá ser distribuido en establecimientos infantiles...

Comentarios, 21/04/2015

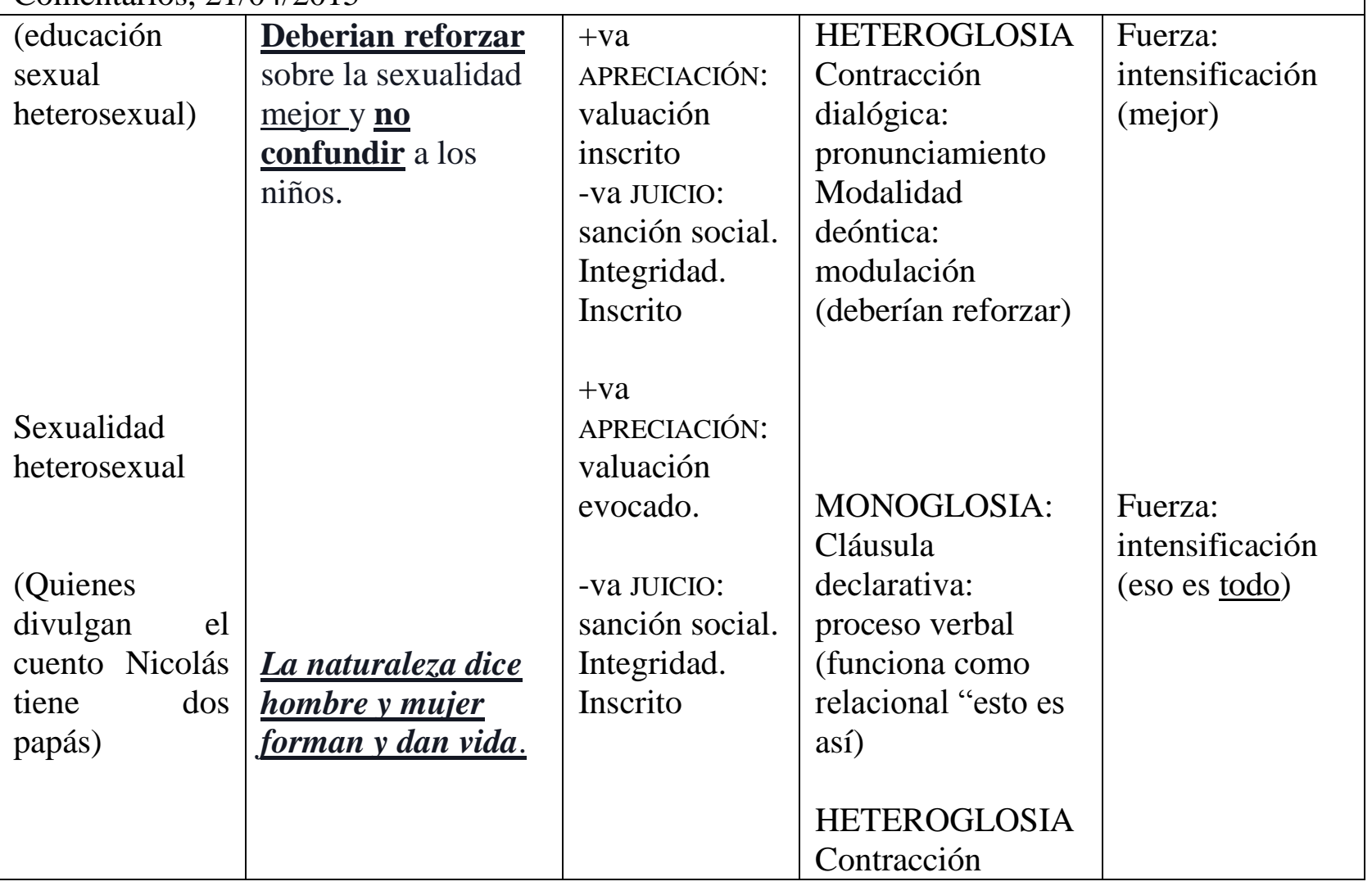


Claudio Araya Seguel

\begin{tabular}{|c|c|c|c|c|}
\hline & $\begin{array}{l}\frac{\text { Eso es todo. Dejen }}{\text { de vulnerar }} \frac{\text { los }}{\text { derechos de los }} \\
\text { niños... }\end{array}$ & & $\begin{array}{l}\text { dialógica: } \\
\text { pronunciamiento } \\
\text { Modalidad } \\
\text { deóntica o } \\
\text { modulación (dejen } \\
\text { de) }\end{array}$ & \\
\hline $\begin{array}{l}\text { Hablar de sexo } \\
\text { a mi hija } \\
\text { pequeña } \\
\text { Inquietud de la } \\
\text { niña } \\
\text { (proceso/cosa) } \\
\text { Organizaciones } \\
\begin{array}{l}\text { gay que } \\
\text { promueven el } \\
\text { cuento }\end{array} \\
\begin{array}{l}\text { Difusión del } \\
\text { cuento }\end{array}\end{array}$ & 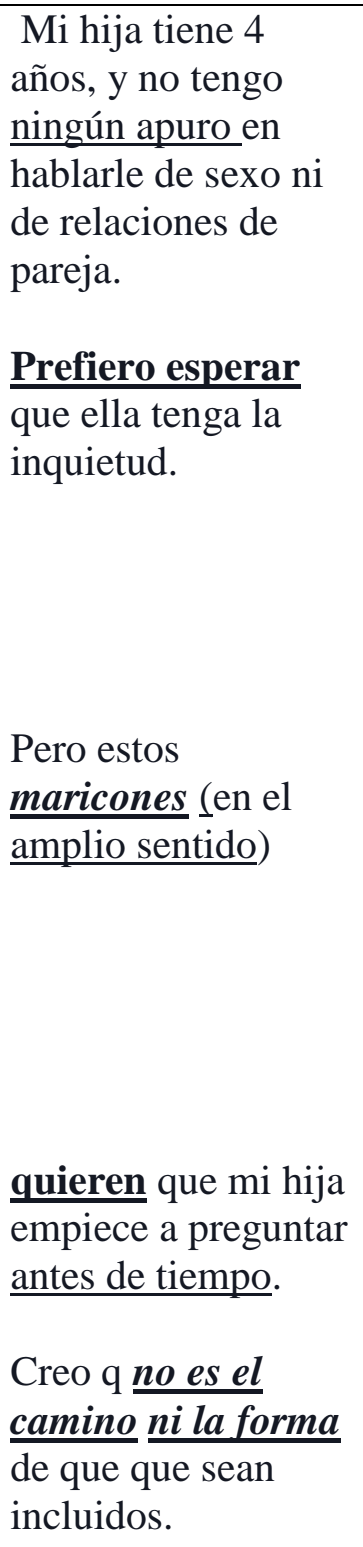 & $\begin{array}{l}\text {-va } \\
\text { APRECIACIÓN: } \\
\text { valuación } \\
\text { +va AFECTO: } \\
\text { irrealis. } \\
\text { inclinación } \\
\text { inscrito } \\
\text {-va JUICIO: } \\
\text { sanción social. } \\
\text { Integridad. } \\
\text { evocado } \\
\text { +va AFECTO: } \\
\text { irrealis. } \\
\text { Inclinación. } \\
\text { inscrito } \\
\text {-va } \\
\text { APRECIACIÓN. } \\
\text { Valuación. } \\
\text { evocado. }\end{array}$ & $\begin{array}{l}\text { HETEROGLOSIA } \\
\text { contracción } \\
\text { dialógica: } \\
\text { pronunciamiento } \\
\text { HETEROGLOSIA: } \\
\text { Contracción } \\
\text { dialógica. } \\
\text { Contraexpectativa. } \\
\text { (pero estos } \\
\text { maricones) }\end{array}$ & $\begin{array}{l}\text { FUERZA: } \\
\text { intensificación. } \\
\text { (Ningún apuro) } \\
\text { FOCO: } \\
\text { desdibujar. } \\
\text { (amplio sentido) } \\
\text { FUERZA: } \\
\text { intensificación. } \\
\text { Extensión } \\
\text { temporal. (Antes } \\
\text { de tiempo) }\end{array}$ \\
\hline $\begin{array}{l}\text { Movilh y } \\
\text { homosexuales }\end{array}$ & $\begin{array}{l}\text { no permitamos que } \\
\text { el movilh y los } \\
\text { degenerados de este } \\
\text { país se salgan con }\end{array}$ & $\begin{array}{l}\text {-va JUICIO: } \\
\text { Sanción } \\
\text { social: } \\
\text { Integridad. X2 }\end{array}$ & $\begin{array}{l}\text { HETEROGLOSIA: } \\
\text { contracción } \\
\text { dialógica. X3 } \\
\text { pronunciamiento }\end{array}$ & \\
\hline
\end{tabular}


Claudio Araya Seguel

\begin{tabular}{|c|c|c|c|c|}
\hline $\begin{array}{l}\text { Libro, su } \\
\text { contenido y } \\
\text { difusión } \\
\text { Movilh y } \\
\text { homosexuales } \\
\text { No envío de } \\
\text { 'retoños' a la } \\
\text { escuela } \\
\text { Valores } \\
\text { heterosexuales } \\
\text { Hombres del } \\
\text { futuro }\end{array}$ & $\begin{array}{l}\text { la suya, } \\
\text { destruyamos este } \\
\text { libro sí cae en } \\
\text { manos de nuestros } \\
\text { niños, no seamos } \\
\text { tolerantes } \\
\text { y por último si se } \\
\text { empeñan que este } \\
\text { se lea en clases, } \\
\text { sencillamente, } \\
\\
\text { aunque sea una } \\
\text { aberración, no } \\
\text { mandemos a nuestro } \\
\text { retoños a la escuela, }\end{array}$ & $\begin{array}{l}\text { inscrito } \\
\text {-va JUICIO: } \\
\text { Integridad. } \\
\text { Evocado. } \\
\text {-va } \\
\text { APRECIACIÓN. } \\
\text { Valuación. } \\
\text { Inscrito.x2 } \\
\text {-va JUICIO: } \\
\text { Sanción } \\
\text { social: } \\
\text { Integridad. } \\
\text { Inscrito. } \\
\text {-va } \\
\text { APRECIACIÓN. } \\
\text { Reacción. } \\
\text { Inscrita } \\
\text { +va AFECTO. } \\
\text { Seguridad. } \\
\text { Inscrito. } \\
\text { +va } \\
\text { APRECIACIÓN: } \\
\text { valuación }\end{array}$ & $\begin{array}{l}\text { HETEROGLOSIA: } \\
\text { contracción } \\
\text { dialógica. } \\
\text { Modulación } \\
\text { obligatoriedad: } \\
\text { (deben tener) }\end{array}$ & $\begin{array}{l}\text { FUERZA: } \\
\text { intensificación. } \\
\text { (Sencillamente) }\end{array}$ \\
\hline $\begin{array}{l}\text { Sociedad actual } \\
\text { Sociedad } \\
\text { tradicional }\end{array}$ & $\begin{array}{l}\text { Que esta pasando en } \\
\text { este mundo loco.... } \\
\text { Integridad, Ética, } \\
\frac{\text { Valores, Moralidad }}{\text { donde esta el punto }} \\
\underline{\text { de referencia }} \\
\\
\text { si ciertos caprichos } \\
\text { de personas y }\end{array}$ & $\begin{array}{l}\text {-va JUICIO: } \\
\text { estima social. } \\
\text { Normalidad. } \\
\text { +va JUICIO: } \\
\text { sanción social. } \\
\text { Integridad. } \\
\text { Inscrita. } \\
\text {-va JUICIO: } \\
\text { sanción social. } \\
\text { Veracidad. } \\
\text { Evocada. } \\
\text {-va AFECTO: } \\
\text { (irrealis). } \\
\text { Inclinación. } \\
\text {-va JUICIO: } \\
\text { sanción social. } \\
\text { Integridad. }\end{array}$ & $\begin{array}{l}\text { HETEROGLOSIA: } \\
\text { Contracción } \\
\text { dialógica. } \\
\text { Pronunciamiento. }\end{array}$ & $\begin{array}{l}\text { FUERZA: } \\
\text { intensificación. }\end{array}$ \\
\hline
\end{tabular}


Claudio Araya Seguel

\begin{tabular}{|c|c|c|c|c|}
\hline $\begin{array}{l}\text { Sociedad } \\
\text { tradicional }\end{array}$ & $\begin{array}{l}\text { grupos quieren } \\
\text { ser la base de un } \\
\text { nuevo punto de } \\
\text { referencia } \\
\\
\text { cambiando } \\
\text { radicalmente todo lo } \\
\text { que llamamos } \\
\text { sociedad civilizada. }\end{array}$ & $\begin{array}{l}\text { Evocado. } \\
\text { +va JUICIO: } \\
\text { estima social. } \\
\text { normalidad }\end{array}$ & & $\begin{array}{l}\text { (cambiando } \\
\text { radicalmente } \\
\text { todo lo que...) }\end{array}$ \\
\hline $\begin{array}{l}\text { Educación de } \\
\text { los niños } \\
\text { Medio } \\
\text { ambiente, } \\
\text { animales, } \\
\text { gente de color, } \\
\text { peruanos, } \\
\text { mujeres } \\
\\
\text { Medio } \\
\text { ambiente, } \\
\text { animales, } \\
\text { gente de color, } \\
\text { peruanos, } \\
\text { mujeres }\end{array}$ & 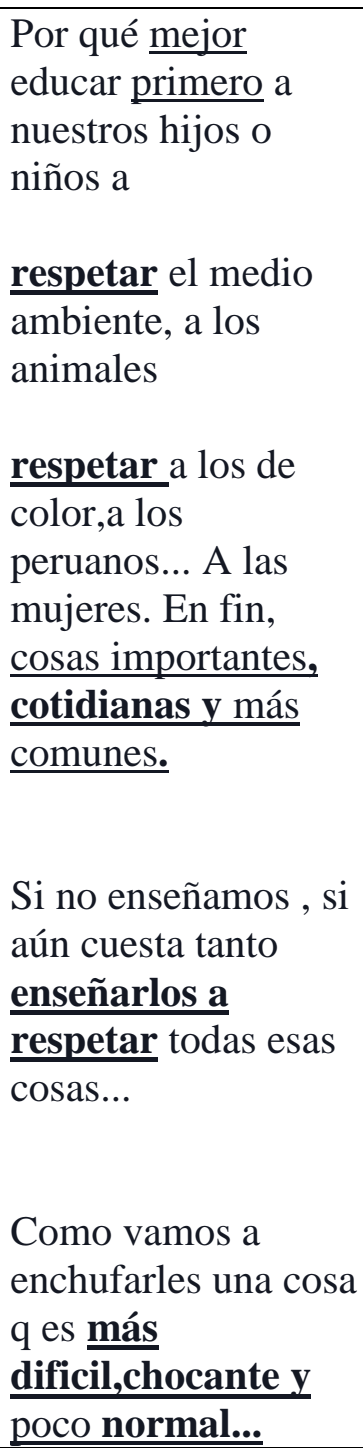 & $\begin{array}{l}\text { +va } \\
\text { APRECIACIÓN: } \\
\text { valuación. } \\
\text { Inscrita. } \\
\text { +va JUICIO: } \\
\text { Estima social. } \\
\text { Normalidad. } \\
\text { Inscrita. } \\
\text { +va JUICIO: } \\
\text { estima social. } \\
\text { Normalidad. } \\
\text { inscrito. } \\
\text {-va JUICIO: } \\
\text { estima social. } \\
\text { Normalidad. } \\
\text { inscrito. X3 }\end{array}$ & $\begin{array}{l}\text { HETEROGLOSIA: } \\
\text { contracción } \\
\text { dialógica. } \\
\text { Pronunciamiento. } \\
\\
\text { HETEROGLOSIA: } \\
\text { contracción } \\
\text { dialógica. } \\
\text { (como nosotros } \\
\text { vamos a } \\
\text { enchufarles) }\end{array}$ & $\begin{array}{l}\text { FUERZA: } \\
\text { intensificación. } \\
\text { (mejor educar } \\
\text { primero a } \\
\text { nuestros hijos) } \\
\text { FUERZA: } \\
\text { intensificación. } \\
\text { Fusión.(cosas } \\
\text { importantes, } \\
\text { cotidianas y más } \\
\text { comunes) } \\
\text { FUERZA: } \\
\text { intensificación. } \\
\text { (más comunes) } \\
\\
\text { FUERZA: } \\
\text { intensificación. } \\
\text { (más difícil) } \\
\text { FUERZA: } \\
\text { cuantificación. } \\
\text { (poco normal) }\end{array}$ \\
\hline
\end{tabular}


Claudio Araya Seguel

\begin{tabular}{|l|l|l|l|l|}
\hline & & & & \\
& & & & \\
\hline
\end{tabular}

Anexo II. Latercera.com

\section{Latercera.com}

Cuento "Nicolás tiene dos papás" podrá ser distribuido en establecimientos infantiles...

Comentarios, 22/10/2014

\begin{tabular}{|c|c|c|c|c|}
\hline $\begin{array}{l}\text { Cuento } \\
\text { homoparental }\end{array}$ & $\begin{array}{l}\text { Esto es una PATRAña, } \\
\text { puedo entender que } \\
\frac{\text { algunos nacen con esa }}{\frac{\text { condicion y }}{\text { tolerarlos.....pero de ahi }}} \\
\text { a PROMOVER } \\
\text { la homosexualidad } \\
\text { como un estilo de vida } \\
\text { u opcion sexual, eso es } \\
\text { una } \underline{\text { ABERRACION }} \\
\text { de la sociedad actual }\end{array}$ & $\begin{array}{l}\text {-va } \\
\text { APRECIACIÓN: } \\
\text { valuación. } \\
\text { Inscrita } \\
\text { +va JUICIO: } \\
\text { estima social. } \\
\text { Normalidad. } \\
\text { Evocada.X2 } \\
\text {-va AFECTO: } \\
\text { inclinación. } \\
\text {-va JUICIO: } \\
\text { estima social. } \\
\text { normalidad. } \\
\text { Inscrita. X2 } \\
\text {-va JUICIO: } \\
\text { sanción } \\
\text { social. } \\
\text { Integridad. }\end{array}$ & $\begin{array}{l}\text { HETEROGLOSIA: } \\
\text { contracción } \\
\text { dialógica. } \\
\text { Refutación. } \\
\text { Contraexpectativa. } \\
\text { (puedo entender } \\
\text { que algunos nacen } \\
\text { con esa condicion y } \\
\text { tolerarlos....pero de } \\
\text { ahi a } \\
\text { PROMOVER) }\end{array}$ & $\begin{array}{l}\text { FUERZA: } \\
\text { cuantificación. } \\
\text { (algunos nacen } \\
\text { con esa } \\
\text { condición) }\end{array}$ \\
\hline $\begin{array}{l}\begin{array}{l}\text { Movilh } \\
\text { (organización) }\end{array} \\
\text { Gobierno } \\
\text { sociedad } \\
\text { Sociedad Rusa }\end{array}$ & $\begin{array}{l}\text { el MOVILH esta } \\
\text { haciendo } \\
\text { PROSELITISMO } \\
\text { contra los } \\
\text { heterosexuales....... } \\
\text { esta claro que el } \\
\text { gobierno y la sociedad } \\
\text { chilena no tienen los } \\
\text { pantalones para parar } \\
\frac{\text { esto, tal como }}{\text { en Re hace }} \\
\text { usia con una ley. }\end{array}$ & $\begin{array}{l}\text {-va JUICIO: } \\
\text { sanción } \\
\text { social. } \\
\text { veracidad. } \\
\text { Inscrita. } \\
\text {-va JUICIO: } \\
\text { estima social. } \\
\text { Tenacidad. } \\
\text { Evocado. } \\
\text { +va JUICIO: } \\
\text { estima social. } \\
\text { Tenacidad. } \\
\text { Evocado. }\end{array}$ & $\begin{array}{l}\text { HETEROGLOSIA: } \\
\text { contracción } \\
\text { dialógica. } \\
\text { Pronunciamiento. }\end{array}$ & $\begin{array}{l}\text { FUERZA: } \\
\text { Intensificación. } \\
\text { (está claro) }\end{array}$ \\
\hline
\end{tabular}


Claudio Araya Seguel

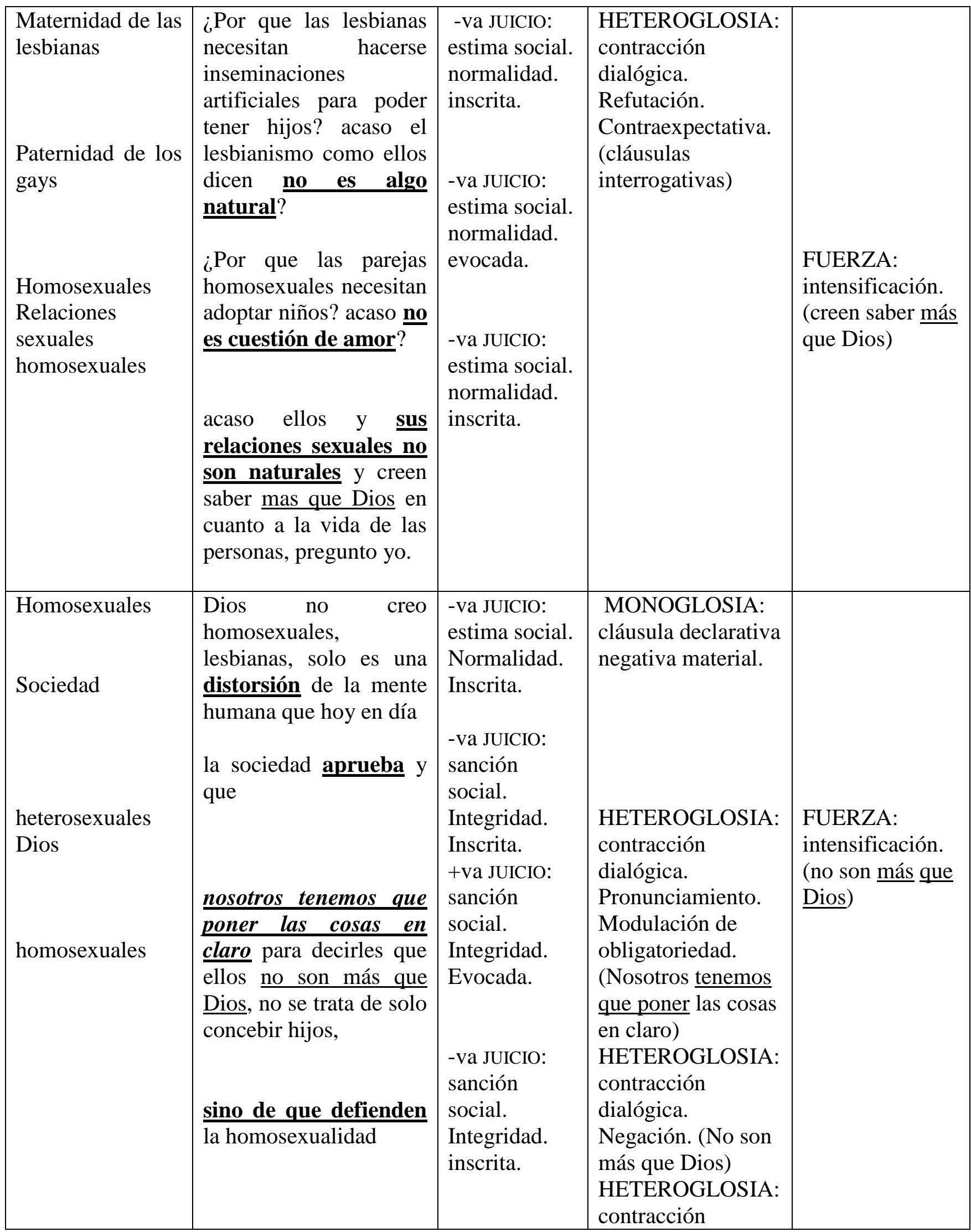




\section{Claudio Araya Seguel}

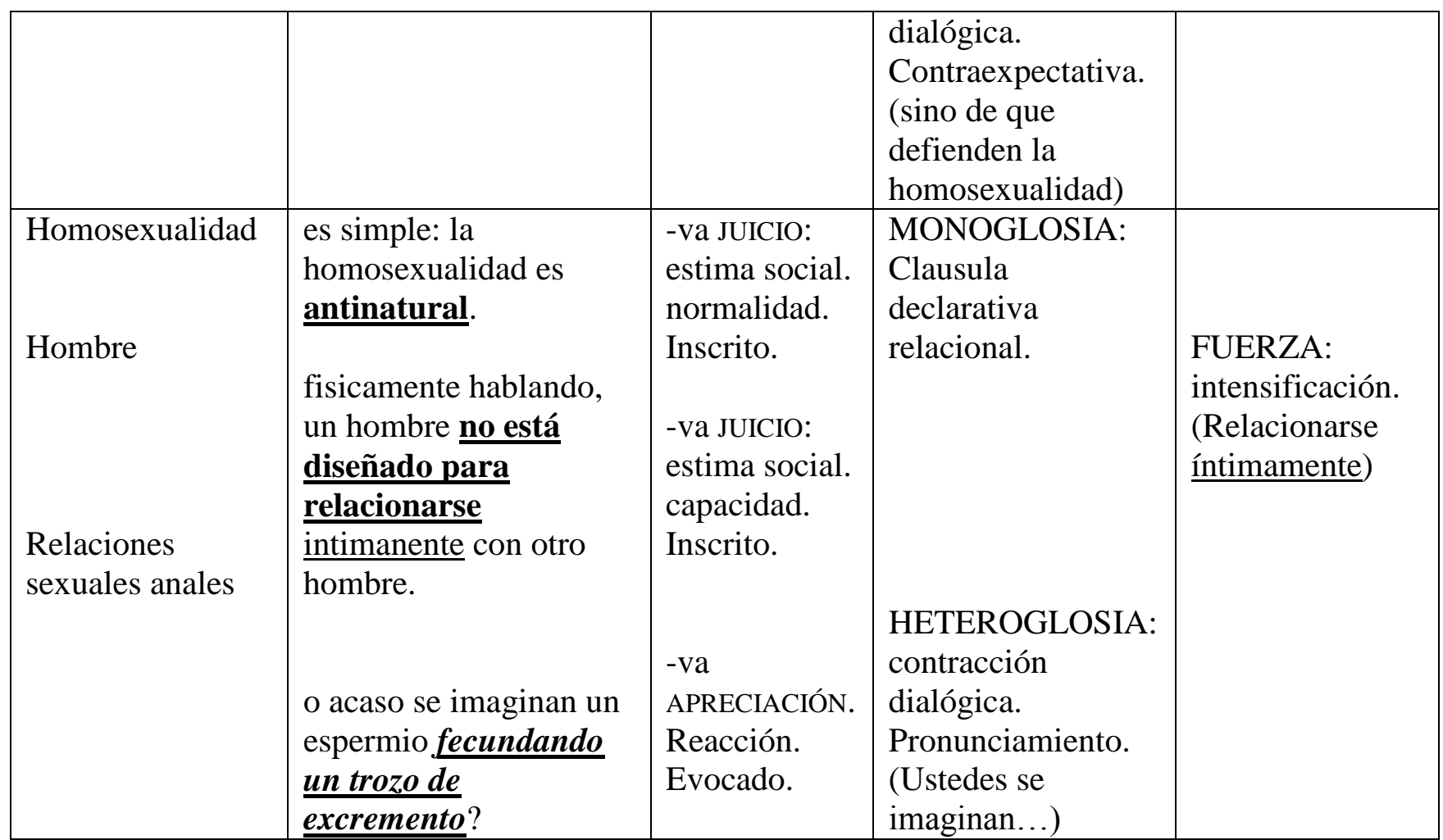

